\title{
Evaluation of Resulting Disability from Back Pain After Childbirth: A Comparison Between Vaginal Delivery and Cesarean Section.
}

mahda khansari ( $\sim$ khansari.mahda@gmail.com )

iran university of social welfare and rehabilitation science https://orcid.org/0000-0002-1574-485X hassan shakeri

university of social welfare and rehabilitation sciences

Amir Masoud Arab

university of social welfare and rehabilitation sciences

Research article

Keywords: Pregnancy-related, low back pain-postpartum, musculoskeletal pain-female-delivery, typefunctional disability index-NVD-CS

Posted Date: June 18th, 2020

DOl: https://doi.org/10.21203/rs.3.rs-27913/v1

License: (9) This work is licensed under a Creative Commons Attribution 4.0 International License. Read Full License 


\section{Abstract}

Objective:

The purpose of this study was to assess the prevalence of postpartum LBP and resulting functional disability in a follow-up program (48 hours later and 3manths after delivery) between 2 methods of delivery.

\section{Background:}

Pregnancy-related low back pain(PLBP) and pelvic girdle pain(PGP) are considered common complications of pregnancy. The long term consequences for women with persistent LBP postpartum are under-investigated. [1-2] the main objective was comparing chronicity ratio and functional disability questionnaires score (Oswestry(OSW), Roland-Morris(RM) and TSK), in after birth and 3manths later stages, between 2 methods of delivery.

\section{Method:}

This is a follow-up study of the cohort including a sample of women who delivered from September 2016 to March 2017 in Sarem women hospital and west Tehran public healthcare centers. A total of 406 new moms received a questionnaire on LBP persistence and in case of a positive answer, the functional disability questionnaires were handed over and also were fallow up by a second questionnaire at approximately 3 months later.

\section{RESULTS:}

The final study sample consists of 406 women that $\mathrm{N}=208(51.5 \%)$ were in the $\mathrm{Cs}$ group and $\mathrm{N}=198(49.2 \%)$ were in the NVD group.

In first stage $\mathrm{N}=164(40.4 \%)$ of total participants reported pain( $C s=81, \mathrm{NVD}=83$ ) while this figures decreased to $\mathrm{N}=150(36.9 \%)$ in second stage ( $C S=74, N V D=76$ ).

The functional disability questionnaire average score in the first phase for the CS group was: $0 S W=14.45$, $\mathrm{RM}=5.67$ And TSK=10.76 and for NVD group was: $\mathrm{OSW}=20.37, \mathrm{RM}=7.67$ and $T S K=11.73$.

In the second stage (3months after delivery) average scores for the CS group were: $O S W=20.47, R M=6.48$ and $T S K=9.71$ and for NVD group was $\mathrm{OSW}=21.56, \mathrm{RM}=6.46$ and $\mathrm{TSK}=11.26$.

\section{CONCLUSION:}

In this study, no relation between delivery type and LBP prevalence was found. OSW and RM average scores had significant difference in first stage, in a way that these scores were higher in NVD ( OSW pvalue $=0.02, \mathrm{RM}$ p-value $=0.03$ ) but in second phase no significant difference was found,( OSW p- 
value $=0.71, \mathrm{RM}$-value $=0.97$ ). TSK scores didn't show any significant difference in any stage ( first stage $p$-value $=0.63$ and second stage $p$-value $=0.61$ ).

\section{Background:}

LBP is an extremely common health problem which is counted as the second major reason for seeking health care. Its prevalence is the same on both genders and is mostly reported in ages 30-50.[1]

For women in addition to general LBP risk factors, two exclusive physiological situations owned the highest LBP reporting ratio, menstruation, and pregnancy.[2-3]

Pregnancy-related low back pain(PLBP), is a common complication of pregnancy and represent a significant health problem among women both during and after pregnancy.[4-6] PLBP resemble low back pain ( LBP) that occur in a none pregnant state. The prevalence of PLBP among pregnant women ranges from 4 to $76.4 \%$ depending on the definition used.[7] it is expected that PLBP appears around 18 weeks of pregnancy which uterus enters abdomen space and gets worse on 24-36 weeks of pregnancy that fetus reaches its pinnacle of growth and weight gaining.[8]

PLBP is not a self-limiting condition in some women.[9] researches has shown that among women developing PLBP about $80 \%$ of them report mild complaints of postpartum LBP whereas $13 \%$ of women report moderate and 7\%have very sever complaints.[4-10]

Predictors of poor outcomes postpartum have shown to be: previous LBP, pelvic trauma history, high level of pain postpartum, high body mass index(BMI), high maternal age, male fetus, smoking. [4-5-11-1213] Morgen etl. in studies on 2006 and 2008 have shown that previous hypermobility, physical strenuous work situation, lack of physical fitness in pregnant women can affect postpartum pain experience.[1415-16] furthermore, there is an increased likelihood of reporting poor health status in women reporting continuous pain postpartum.[4-5]consequently, women with recurrent or continuous postpartum LBP may have a poor prognosis in future disability.

The world health organization(WHO) consider musculoskeletal condition to be the second greatest cause of years lived with disability (YLD), where low back pain rank number one of the top 10 leading causes of global YLD.[4-17]

Spine related problems constitute large individual and social costs as a result of chronic musculoskeletal pain. Besides international studies have reported a higher utilization of health services concerning chronic pain.[4-17-18]

Even though not all women with PLBP during pregnancy are prone to turn to chronic causes and most studies focus on the persistence of pain, we decide in this study to investigate both persistence and disability rate in PLBP women with a 3months follow up. 


\section{Method:}

\section{Design:}

This is a follow-up cohort study of 406 women who delivered in west Tehran from September 2016 to March 2017. The sample was collected from Sarem women hospital and west Tehran health centers. an overview of the entire sample group is illustrated in Table 1. Basic data were collected through a questionnaire near after delivery (up to 48 hours later) and women who reported PLBP at baseline were thereafter invited to complete standard functional disability index questionnaires in step 1 . For the second step, all participants received a questionnaire about their pain 3 months later and in case of any pain, the disability index questionnaires were completed.

Table 1

participants overview

\begin{tabular}{|lll|}
\hline total & Caesarean & NVD \\
\hline 406 & 208 & 198 \\
\hline
\end{tabular}

The inclusion criteria for this study were:

1. Women who experienced first delivery regardless of age

2. Singleton pregnancy

3. No disabling LBP history before pregnancy

The exclusion criteria were as listed below:

1. Not first delivery

2. Polygamy

3. Severe LBP before pregnancy

4. Women who suffer from specific LBP like discopathy, spondylosis, fracture, vertebral dislocation, and infection.

5. Complicated and device-assisted delivery

6. Complicated pregnancy

\section{DEFINITION OF VARIABLES:}

- LBP: information about pain experience in both phases were self-reported and a VAS diagram was used to indicate the severity of pain. this pain should be in the lumbar region without any referring pain to extremities.

- Delivery method: women with both delivery method were interviewed and those who have complication through the delivery process were excluded because the number of injuries were unpredictable. 
- Functional disability: scores of standardized translated RM and OSW questionnaires were used to assess functional disability.

- Movement fear: scores of standardized translated version of TSK questionnaire was used as an index for fear role in movement avoidance as a necessary functional factor.

\section{STATISTICAL METHODS:}

IBMSPSS software package was used for statistical calculations.

For descriptive statistics, mean, standard deviation, relative frequency and absolute frequency was calculated.

To describe numerical variables, the mean was counted as a central tendency index and the standard deviation was counted as dispersion index.

\section{Results:}

\section{DESCRIPTIVE:}

Without considering the delivery method, total LBP suffering participants in the first stage was $40.4 \%$ which declined to $36.9 \%$ in the second stage. (Table 2) The same pattern was witnessed in both groups, from $38.9-35.6 \%$ in CS (Table 3 ) and from $41.9-38.4 \%$ in the NVD group. (table 4)

Table 2

LBP report without considering the delivery method

\begin{tabular}{|llll|}
\hline variable & status & Absolute freq. & relative freq. \\
\hline First stage(after childbirth) & No LBP & 242 & 59.6 \\
\cline { 2 - 4 } & LBP & 164 & 40.4 \\
\hline Second stage(3months & NO LBP & 252 & 62.1 \\
\cline { 2 - 4 } later) & LBP & 150 & 36.9 \\
\hline
\end{tabular}

Table 3

LBP report in CS group

\begin{tabular}{|llll|}
\hline variable & status & Absolute freq. & relative freq. \\
\hline First stage(after childbirth) & No LBP & 127 & 61.1 \\
\cline { 2 - 5 } & LBP & 81 & 38.9 \\
Second stage(3months later) & NO LBP & 134 & 64.4 \\
\cline { 2 - 4 } & LBP & 74 & 35.6 \\
\hline
\end{tabular}

Questionnaire scores (OSW, RM, and TSK) was used as an index for resulted disability. Mean and standard deviation was counted as change reference. 
OSW mean for CS group was changed from 14.45 to 20.47 and SD from 13.39 to 18,12 . RM index mean, marginally climbed up from 5.67 to 6.48 and SD climbed from 5.84 to 6.50 . TSK questionnaire mean score changed from 36.43 to 37.45 and SD from 10.76 to 9.71.( Table 5)

Table 4

$\angle B P$ report in NVD group

\begin{tabular}{|llll|}
\hline variable & status & $\begin{array}{l}\text { Absolute } \\
\text { freq }\end{array}$ & $\begin{array}{l}\text { relative } \\
\text { freq. }\end{array}$ \\
\hline $\begin{array}{l}\text { First stage(after } \\
\text { childbirth }\end{array}$ & No LBP & 115 & 58.1 \\
\cline { 2 - 4 } & LBP & 83 & 41.9 \\
$\begin{array}{l}\text { Second stage(3months } \\
\text { later) }\end{array}$ & No LBP & 118 & 59.6 \\
\hline & LBP & 76 & 38.4 \\
\hline
\end{tabular}

NVD group trait was a little different. OSW mean show a negligible reduction from 20.37 to 21.56 and SD from 20.88 to 18.71 . RM index mean fallowed the same trend and mean score fall from 7.67 to 6.46 and SD from 5.96 to 5.42.but about TSK index the matter is a little bit different and we witnessed a raising behavior for mean score and it increased from 35,58 to 36,52 but SD score illustrated a marginal falling behavior from 11.73 to 11.26.(Table 6)

Table 5

disability index in CS group

\begin{tabular}{|lllll|}
\hline variable & mean & SD & Min. & Max. \\
\hline OSW 1 & 14.45 & 13.30 & 0 & 74 \\
\hline OSW 2 & 20.47 & 18.12 & 0 & 75 \\
RM 1 & 5.67 & 5.84 & 0 & 22 \\
RM 2 & 6.48 & 6.50 & 0 & 21 \\
TSK 1 & 36.43 & 10.76 & 17 & 64 \\
TSK 2 & 37.45 & 9.71 & 17 & 55 \\
\hline
\end{tabular}

ANALYTICAL DATA:

About delivery type relation with LBP, in both stages, we didn't find any significant relation.(first stage $p$ value $=0.54$, second stage $p$-value $=0.45)($ Table 7 and 8$)$ 
Table 6

disability index in NVD group

\begin{tabular}{|lllll|}
\hline variable & Mean & SD & Min. & Max. \\
\hline OSW 1 & 20.37 & 20.88 & 2 & 86 \\
\hline OSW 2 & 21.56 & 18.71 & 0 & 75 \\
\hline RM 1 & 7.62 & 5.96 & 0 & 20 \\
\hline RM 2 & 6.46 & 5.42 & 1 & 21 \\
\hline TSK 1 & 35.58 & 11.73 & 18 & 66 \\
\hline TSK 2 & 36.52 & 11.26 & 17 & 57 \\
\hline
\end{tabular}

Table 7

LBP persistence relation with delivery type (stage

1)

\begin{tabular}{|llll|}
\hline Delivery type & LBP & No LBP & Chi-square \\
\cline { 1 - 3 } CS & 81 & 127 & 0.54 \\
\cline { 1 - 3 } NVD & 83 & 115 & \\
\hline
\end{tabular}

As it is shown in Table 9, there is a significant difference in OSW and TSK scores in the CS group between stages, in a way that the mean scores of these questionnaires were higher in the second stage.

Table 8

LBP persistence relation with delivery type (stage

2)

\begin{tabular}{|llll|}
\hline Delivery type & LBP & No LBP & Chi-square \\
\cline { 1 - 3 } CS & 74 & 134 & 0.45 \\
\cline { 1 - 3 } NVD & 76 & 118 & \\
\hline
\end{tabular}

But in the NVD group, we didn't witness any significant difference in questionnaire scores between 2 stages. (Table 10)

Table 9

CS in group questionnaires scores

comparison

\begin{tabular}{|lll|}
\hline questionnaire & Mean difference & Sig. \\
\hline OSW & -4.90 & 0.01 \\
\hline RM & 0.18 & 0.77 \\
\hline TSK & -3.14 & 0.00 \\
\hline
\end{tabular}

In comparing 2 groups of questionnaire scores, that disability index is higher in the NVD group in stage 1. (OSW p-value $=0.02$, RM p-value $=0.03$ ) but in the second phase, no significant difference was found. ( 
OSW p-value $=0.71, \mathrm{RM}$-value $=0.97$, TSK p-value $=0.61)($ Table 11 and 12$)$

Table 10

NVD in group questionnaires scores comparison

\begin{tabular}{|lll|}
\hline questionnaire & Mean difference & Sig. \\
\hline OSW & 1.60 & 0.56 \\
RM & 1.64 & 0.07 \\
TSK & -1.91 & 0.06 \\
\hline
\end{tabular}

Table 11

questionnaires scores comparison between 2 groups (stage 1)

\begin{tabular}{|c|c|c|c|}
\hline \multirow[t]{2}{*}{ variable } & \multicolumn{2}{|l|}{ Group } & \multirow[t]{2}{*}{$p$-value } \\
\hline & $C S$ & $N V D$ & \\
\hline OSW & 14.47 & 20.87 & 0.02 \\
\hline$R M$ & 5.67 & 7.67 & 0.03 \\
\hline TSK & 36.43 & 35.58 & 0.63 \\
\hline
\end{tabular}

Table 12

questionnaires scores comparison between 2 groups (stage 2)

\begin{tabular}{|c|c|c|c|}
\hline \multirow[t]{2}{*}{ variable } & \multicolumn{2}{|l|}{ Group } & \multirow[t]{2}{*}{$p$-value } \\
\hline & $c S$ & $N V D$ & \\
\hline osW & 20.47 & 21.58 & 0.71 \\
\hline$R M$ & 6.48 & 6.46 & 0.97 \\
\hline TSK & 37.45 & 36.59 & 0.61 \\
\hline
\end{tabular}

\section{Discussion:}

In this study, we had 406 participants who 208 were in the CS group and 198 in the NVD group.

\section{AFTER BIRTH LBP:}

Generally and without considering the delivery method, $40.4 \%$ of participants reported LBP that this number fell to $36.9 \%$ (table 1). This finding confirms the result of past studies which stated some pregnancy-related injuries heal by time. like Woolhouse etl. Study in 2012 which was done on 1502 participants with 3, 6 and 12 months postpartum follow-ups for detecting LBP persistence and they found out that most reported pain was healed by time.[19] 
There are so many factors for post-delivery LBP. For example Breen and etl. In a study on 1402 women in 24-48 hours after delivery with 1-2 months follow up, reckoned that sever PLBP, early onset of pain in pregnancy, excessive weight gain during pregnancy and late weight loss after delivery are effective for chronicity of LBP after birth.[20] In nutshell, after birth pain is expected to recover by the time even without any medical intervention.

Also, we found a descending trend in each delivery method reported LBP by the time, for CS from $38.9 \%$ to $35.6 \%$ (table 2) and in the NVD group from $41.9 \%$ to $38.4 \%$ (table 3 ).

In this study, we didn't find any relation between the delivery type and postpartum LBP.

\section{PAIN RELATED FUNCTIONAL DISABILITY:}

As mentioned before, the pain reporting rate decreased by time, but this doesn't mean that functional disability index scores, fell as well.

In a group study for the CS, the method illustrated that despite a declining rate of reported pain, an increase in TSK and OSW scores were seen. duing cesarean procedure, some vital supportive tissue like abdominal superficial and deep fascia is cut and abdominal wall muscles functional ability are affected, some disturbance in spinal column stability is expected. The result of supportive tissue alteration is some difficulties in a transitional position. moreover, experienced pain in some casual positions may stop new mom from some movement.

In the NVD group, no significant relation was found in 2 stages, which means despite pain decrease, no change in disability index score were found.

To sum up, we get into this conclusion that pain reduction is not necessarily associated with disability index scores decrease.

\section{COMPARING DISABILITY BETWEEN 2 DELIVERY METHODS:}

In our study, we detect a significant relationship between the two delivery methods.

In the first stage, disability index scores, in a way that NVD group owned a higher score.(OSW pvalue $=0.02$, RM p-value $=0.03$ ) (table 11) and also NVD group, pain reporting was higher than the CS group.(NVD=41.9\%, CS $=38.9 \%)$. So we can get to this conclusion that in the first stage, the NVD group not only has a higher rate of pain but also a higher disability score.

To highlight the possible reasons of this difference lies in both methods procedure:

During the NVD method, major force is on pelvic girdle, lower back and vaginal pathways that can lead to on some sacral and pelvic neurons, pubic symphysis diastasis and unspecific low back pain. High imposed stress on pelvic girdle and surroundings can cause illiosacral joint instability. Post NVD ct scans indicate abnormal pubic symphysis opening and gas accumulation. [21] Long labor time may lead to 
priformis muscle contusion.[22-23] moreover, sometimes episiotomy incision leads to some adhesion that can affect pelvic floor muscle sufficiency and as we know, pelvic girdle muscles are important in lumbar stability, so their insufficiency can cause to functional instability.

CS is counted as a major abdominal surgery. incision is inserted on the upper pubic area. Central abdominal wall muscle insertion is on the pubic bone area, so these muscles play an important role in the dynamic stability of low back and pelvic girdle. $\mathrm{C}$ section incision can affect the biomechanics of back and pelvis by possible inhibition of rectus abdominis muscle in reaction to surgical procedure. [24] during CS superficial and deep fascia are cut and this may present some myofascial adhesion which is the main reason for myofascial pattern complications.adhesion in fascial pattern may cause LBP, unilateral or bilateral hip pain and lower cross syndromes.

As mentioned above, both delivery methods have considerable effects on stabilizing factors of body core. Due to major effects of CS on the abdominal wall, we expected more pain and disability in this group, especially immediately postpartum, but the study results showed that the effect of pressures during NVD procedure, make new moms more suffering from pain.

In some studies, the imposed pressures on pelvic and low back during the NVD process are supposed as major predisposing factors for future chronic SI joint, pubic symphysis and sacrococxygeous pain.[25-26]

As we know every surgery underlie chronic pain. A study result reported $4-10 \%$ of chronic pain in the CS group, especially if they had experienced prior CS.[24] This phenomenon may result in post-operation scar adhesion and movement patterns disturbance.

\section{Conclusion:}

In summary, the main finding of this cohort study was that despite general concepts, the delivery method doesn't have any relation to pain chronicity incidence, however, in the early-stage rate of reported pain and disability scores were higher in NVD. To sum up results:

- Not considering delivery method, $40.4 \%$ of new moms experienced post-delivery pain which this number fell to $36.9 \% 3$ months later.

- No relation was found between the delivery method and LBP persistence. (table 7 and 8 )

- In group study for the CS, the method showed, despite pain rate decrease functional disability scores increased in stage 2 .

- In a group study for the NVD, the method showed no significant relation to functional disability index scores in two stages.

- Between-group study in the first stage illustrated a significant relation between OSW and RM scores, in a way that the NVD group owned higher scores.

- We didn't find any significant relationships in a between-group study in the second stage on the two groups questionnaire score. 
SUGGESTIONS AND LIMITATIONS:

- Higher number of participants and longer fallow ups may lead to a more accurate statistical results.

- Studies that inspects more musculoskeletal disorders seems necessary to make a more general vision about postpartum complications.

\section{Abbriviations:}

NVD = natural vaginal delivery

CS $=$ cesarean section

LBP = low back pain

OSW = Oswestry disability index

$\mathrm{RM}=$ Roland- Morris disability scale

TSK = Tempa scale for kinesiophobia

\section{Declarations:}

\section{- ethical approval and consent to participate:}

this study was approved by the Ethics committee, at the social welfare and rehabilitation sciences university (Tehran, Iran): 931204002

\section{- availability of data and materials:}

the dataset and/or analyzed during the cureent study available from the corresponding author on reasonable request.

- Competing interest:

The author declare that they have no competing interest.

\section{- Funding:}

Not applicable.

\section{- Authors contribution:}




\section{- Acknowledgment:}

Not applicable

\section{References}

1. -Borenstein D.Epidemiology, etiology, diagnostic evaluation, and treatment of low back pain. Current opinion in Rheumatology.1997;9(2).).

2. -Orvietro RAchironABen-Rafael Z. Gelernter L.Achiron R.Low back pain of pregnancy. Acta Obstetricia et Gynecologica scandinavica. 1994;73(3):209-14.

3. -Borg-stein. J.Dugan S.Musculoskeletal disorders of pregnancy. delivery postpartumPhysical medicine rehabilitation clinics of North America. 2007;18(3):459-76.

4. -Bergstrom C, Persson M, Morgen I.Sick leave and healthcare utilization in women reported pregnancy-related low back pain and/or pelvic girdle pain at 14 months postpartum.chiropractic and manual therapies.2016;24:7.

5. - Borg-stein. J.Dugan S.Musculoskeletal disorders of pregnancy. delivery postpartumPhysical medicine rehabilitation clinics of North America. 2007;18(3):459-76.

6. -Noren L, Ostgaard S, Johansson G, Ostgaard HC.Lumbar back and posterior pelvic pain during pregnancy: a 3-years follow-up.Eur spine J.2002;11:267 - 71.

7. -Kanakari NK, Roberts CS, Giannoudis PV. Pregnancy-related pelvic girdle pain: an update. BMC med. 2011;9:15.

8. - Borgstrom CPersson M.Morgen I.pregnancy related low back pain and pelvic girdle pain approximately 14 monthes after pregnancy-pain status.BMC pregnancy and childbirth.2014;14-48.

9. - Borgstrom CPersson M.Morgen I.pregnancy related low back pain and pelvic girdle pain approximately 14 monthes after pregnancy-pain status.BMC pregnancy and childbirth.2014;14-48.

10. - Wu WH, Meijer OG, Uegaki K, Mens JM, Van Dieen JH, Wuisman PL, et al.Pregnancy related pelvic girdle pain(PPP): terminology, clinical presentation, and prevalence.Eur spine J.2004;13:575 - 89.

11. Pelvic girdle pain and lumbar pain in

- Gutke A, Josefsson A, Oberg B. Pelvic girdle pain and lumbar pain in.

12. relation to postpartum depressive symptoms. Spine (Phila Pa 1976). 2007;32:1430-6.

13. Risk factors in Albert HB, Godskesen M, Korsholm L, Westergaard JG. Risk factors in.

14. developing pregnancy-related pelvic girdle pain. Acta Obstet Gynecol Scand. 2006;85:539-44.

15. Juhl M, Andersen PK, Olsen J, Andersen AM. Psychosocial and physical work environment, and risk of pelvic pain in pregnancy. A study within the Danish national birth cohort. J Epidemiol Community 
Health. 2005;59:580-5.

16. Mogren IM. BMI, pain, and hyper-mobility are determinants of long-term outcome for women with low back pain and pelvic pain during pregnancy. Eur Spine J. 2006;15:1093-102.

17. Mogren I. Perceived health, sick leave, psychosocial situation, and sexual life in women with lowback pain and pelvic pain during pregnancy. Acta Obstet Gynecol Scand. 2006;85:647-56.

18. Mogren IM. Physical activity and persistent low back pain and pelvic pain.

19. postpartum. BMC Public Health. 2008;8:417.

20. Years

Vos T, Flaxman AD, Naghavi M, Lozano R, Michaud C, Ezzati M, et al. Years.

21. lived with. disability (YLDs) for 1160 sequelae of 289 diseases and injuries 1990-2010: a systematic analysis for the Global Burden of Disease Study 2010. Lancet. 2012;380:2163-96.

22. - Eriksen J, Sjogren P, Ekholm O, Rasmussen NK. Health care utilization among individuals reporting long-term pain: an epidemiological study based on Danish National Health Surveys. Eur J Pain (Lond Engl). 2004;8:517-23.

23. - Woolhouse HPerlen S.Gartland D.Brown S.Physical health and recovery in the first 18 months postpartum.BIRTH.2012;39(3):221.

24. - Breen TRansil B.Groves P.Oriol N.Factors associated with back pain after childbirth.Anesthesiology.1994;81:29-34.

25. - Proisy M. Rouli A. Ruoult H. Rozel C. Guggenbuhl P. Jacob D. Guilin RImaging of musculoskeletal disorders related to pregnancyAJR. 2014;202:828-38.

26. - Ku A, Kern H, Lachman E, Nagler W. Sciatic nerve impingement from piriformis hematoma due to prolonged labor. Muscle Nerve. 1995;18:789-90.

27. - Kinahan AM, Douglas MJ. Piriformis myositis mimicking epidural abscess in a parturient. Can J Anaesth. 1995;42:240-5.

28. - Bjelland EK, Stuge B, Vangen S, et al. Mode of delivery and persistence of pelvic girdle syndrome 6 months postpartum. Am J Obstet Gynecol. 2013;208:298.e1-7.

29. -Kowalk DL, Perdue PS, Bourgeois FJ, Whitehill R. Disruption of the symphysis pubis during vaginal delivery: a case report. J Bone Joint Surg Am. 1996;78:1746-8.

30. 5226-Maigne JY, Rusakiewicz F, Diouf M. Postpartum coccydynia: a case series study of 57 women. Eur J Phys Rehabil Med. 2012;48:387-92.

31. \. 